\title{
First Report of Colletotrichum truncatum Causing Stem Cankers on Jatropha curcas in Burkina Faso
}

C. A. Ellison, CABI Europe-UK, Bakeham Lane, Egham, Surrey, TW20 9TY, UK; A. Sawadogo, Faso Biocarburant Fondation, Leo, Sissili, Burkina Faso; S. Braman, Association pour la Promotion du Jatropha et des Energies Renouvelables (APROJER) Banfora, Comoé, Burkina Faso; and S. Nacro, Faso Biocarburant Fondation, Leo, Sissili, Burkina Faso

\begin{abstract}
Ellison, C. A., Sawadogo, A., Braman, S., and Nacro, S. 2015. First report of Colletotrichum truncatum causing stem cankers on Jatropha curcas in Burkina Faso. Plant Dis. 99:14-20.

A new disease was identified on the biofuel crop Jatropha curcas in 2012 in Burkina Faso that is causing serious yield losses. The disease was found to be widespread in both Sissili and Comoé Provinces. It causes characteristic leaf lesions, fruit necrosis, and cankers on young stems and branches. There was evidence of multiple infections on plants over the growing season, with regrowth evident from below old cankers, but there was little fruit production from infected branches. A detailed monitoring and assessment was undertaken of the disease progress in a severely infected field, over a 7 -week period. The disease symptoms progressed from chlorosis through a necrotic phase and, in

approximately $83 \%$ of replicates, stem cankers developed that resulted in dieback and lodging of branches. Colletotrichum truncatum and a member of the species complex C. gloeosporioides sensu lato were consistently isolated from fresh stem samples showing early symptoms (chlorosis). Koch's postulates were undertaken, to establish the pathogenicity of the two species. No symptoms were observed on plants inoculated with $C$. gloeosporioides; however, leaf and stem lesions developed after inoculation with $C$. truncatum, which was reisolated from the diseased tissue, confirming it as the disease-causing agent. Preliminary management practices for the disease are proposed.
\end{abstract}

Jatropha curcas (jatropha), a perennial shrub or small tree from the family Euphorbiaceae, is being widely planted in Asia, Africa, and Central America as a biofuel crop; it produces oil-rich seed that can be processed easily to produce biodiesel. Jatropha is being promoted as a cash crop for farmers, particularly in arid regions or on marginal land, due to its perceived hardiness and drought tolerance. A popular misconception has been perpetuated that jatropha is largely resistant to pests and diseases because of its toxicity. The evidence is now mounting that this is far from the reality within the relatively new plantation production systems around the globe (1). Recent work has established that, in the center of origin or diversity of jatropha, purportedly Mexico, a varied and extensive range of pathogens is found to infect the plant, including co-evolved species (such as rusts). Until recently, in Asia and Africa, where jatropha is an introduced species, only leaf spots with low plant impact were recorded in fungal herbaria databases (http://nt.arsgrin.gov/fungaldatabases/index.cfm). However, with mass planting has come an increase in serious pathogen problems, particularly stem cankers and root rot pathogens (species of Phytophthora, Rhizoctonia, and Colletotrichum are all implicated in the disease complexes). Typically, these pathogens can attack a number of plant species and are likely to have "jumped" onto jatropha from endemic euphorbias and closely related crop species such as cassava; although, in many cases, this still needs to be substantiated.

In mid-2012, reports were first received from Sissili Province, Burkina Faso of severe dieback in a small jatropha plantation. Such symptoms had not been reported on this crop before in Burkina Faso, and insects did not appear to be associated with the stem

Corresponding author: C. A. Ellison, E-mail: c.ellison@cabi.org

Accepted for publication 15 May 2014.

http://dx.doi.org/10.1094/PDIS-02-14-0181-RE

(C) 2015 The American Phytopathological Society cankers (S. Nacro, personal observation). In September 2012, a survey was undertaken over a 6-day period of two jatrophagrowing provinces in Burkina Faso (Sissili and Comoé) to assess the problem.

\section{Materials and Methods}

Survey. Sites in Sissili were selected by staff from Faso Biocarburant Fondation from those farms that the Foundation supports. Jatropha was being grown in monoculture, in fields usually less than a hectare in size, and the plants were 3 years old. Eleven sites were visited within a $20-\mathrm{km}$ radius of Leo; initially, sites where the suspected disease had been observed first were visited in order to collect samples of damaged tissue for analysis and, subsequently, other sites were included in the survey in order to assess the extent of the problem. In Comoé, seven sites were visited within a $50-\mathrm{km}$ radius of Banfora, selected by staff from the corporate foundation Association pour la Promotion du Jatropha et des Energies Renouvelables (APROJER). There was no information on whether the same disease problem was present prior to the survey.

At each site visited, an assessment was made of the overall level of disease incidence. A W-shaped transect was made through each field, and each plant along the transect was assessed for disease symptoms; at least 30 plants were assessed per site. The results were grouped into four categories: high $=>80 \%$ of trees with at least one branch infected, medium $=$ symptoms visible on 80 to $20 \%$ of trees, low $=$ symptoms visible on $<20 \%$ of trees; and no disease observed. Where symptoms were observed, sections approximately $20 \mathrm{~cm}$ in length were cut from branches showing the suspected disease. At sites where disease incidence was medium to high, at least four samples were collected from individual trees separated by at least 5 $\mathrm{m}$. At sites with low incidence, fewer samples were collected. Samples of different developmental stages of the suspected disease were collected, and the sections included tissue from below the leading edge and, where present, into the necrotic tissue.

Field monitoring. At the site in Mouna, near Leo, in Sissili Province $\left(11^{\circ} 15.414^{\prime} \mathrm{N}, 002^{\circ} 07.664^{\prime} \mathrm{W}\right)$, a monitoring experiment 
was set up in 2012 to follow disease development from September until the end of the growing season (December), when the plants dropped their leaves and pruning would be undertaken. The aim was to confirm that the different symptoms observed in the field were part of the same disease syndrome and to discover the speed of disease progress. Thirty trees that had at least one branch with potential early-stage branch infections exhibiting chlorotic lesions were selected at random at the site. These were labeled individually and grouped into five plots within the field to aid their subsequent location, and images were taken of each infection weekly over a 2-month period. The images were assessed visually and symptom development was recorded.

Isolation and identification. In the CABI quarantine-containment unit in Egham, United Kingdom, samples were taken from early-stage branch infections-where only chlorosis was evidentas well as from the leading edge of stem cankers and leaf lesions to try and obtain a culture of the causal agent of the disease. All the samples that were collected were observed using a dissecting microscope and, where present (or encouraged by placing samples in a high humid environment for $12 \mathrm{~h}$ ), spore-producing bodies were examined using a compound microscope. Isolation of the potential causal agent of the disease symptoms was made from one to three samples (depending on the quality and quantity of the collected material) collected at each of the 14 sites with disease incidence. Branch samples ( 2 and 7 days old) were first wiped with a tissue soaked in ethanol; then, the outer bark was carefully removed, using a sterilized scalpel blade, from the leading edge of infections or chlorotic areas. Small sections, approximately 5 by 5 by $2 \mathrm{~mm}$, were cut from the tissue just below the bark, surface sterilized by placing them in sodium hypochlorite $(1.4 \%$ available chlorine) for approximately $2 \mathrm{~min}$, rinsed in sterile distilled water (SDW) twice, then placed on tap water agar (TWA) containing the
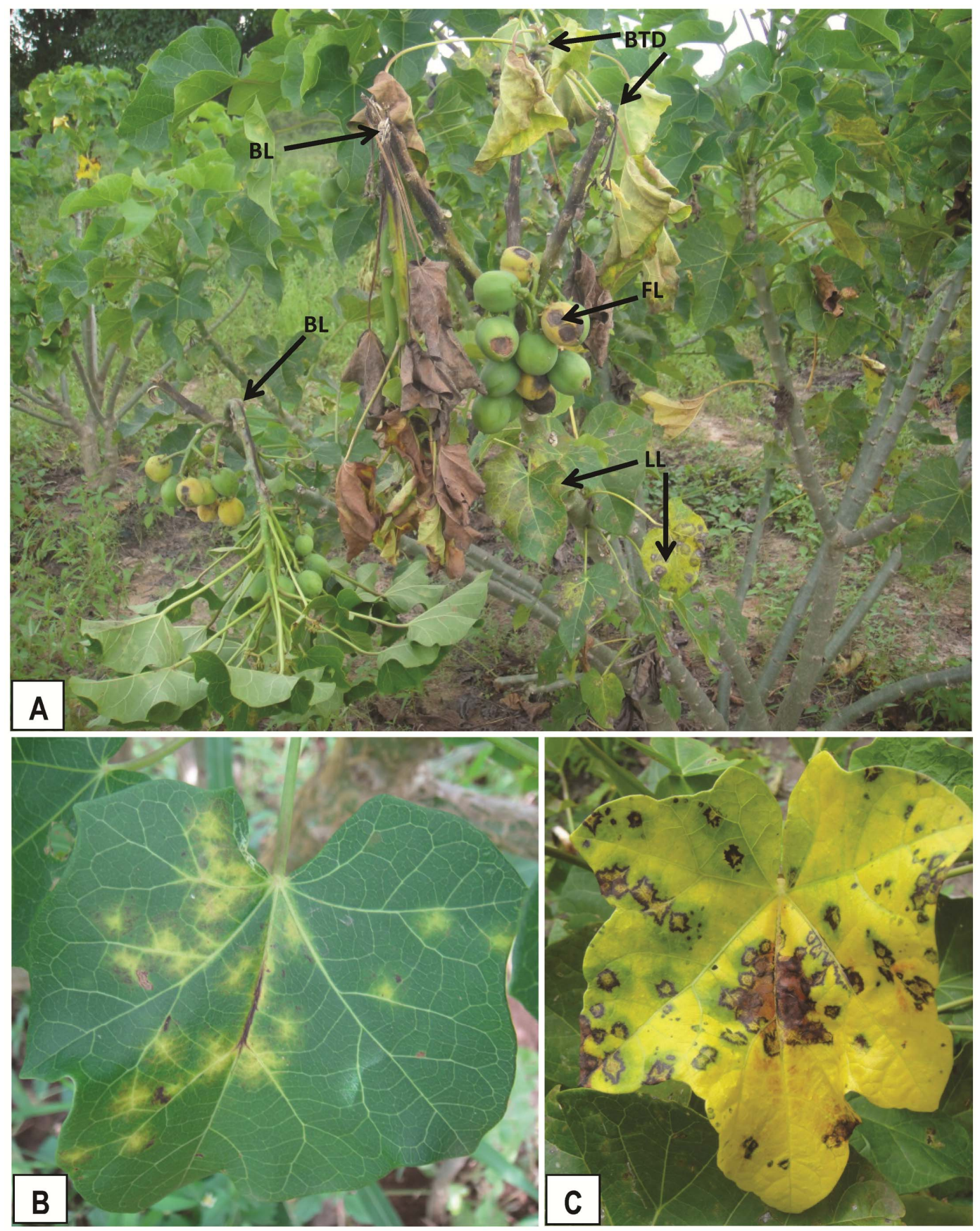

Fig. 1. Characteristic field symptoms of leaf, fruit, and branch infection of Jatropha curcas caused by Colletotrichum truncatum. A, Advanced branch infection, and fruit and leaf infection (BL = branch lodging, BTD = branch tip dieback, FL = fruit lesions, and $\mathrm{LL}=$ leaf lesions); B, early leaf infection, showing chlorosis; $\mathrm{C}$, advanced leaf infection, showing necrosis. 
antibiotics chloramphenicol (200 ppm) and penicillin G (100 ppm) (7). In addition, isolations were made from puncture wounds on branches likely to have been caused by insects feeding on the young shoots (where chlorosis was only just starting to be visible around the wound) and from fruit and leaf lesions using the same surface-sterilizing technique as above. Mycelium that grew from the samples onto the agar was subcultured onto potato carrot agar (PCA) plates (20 g of potato, carrot, and Oxoid agar number 3 added to $1,000 \mathrm{ml}$ of tap water, with the same antibiotics as TWA added), and placed under ultraviolet and cool white light fluorescent tubes to encourage sporulation (7). Cultures were purified and all were assessed morphologically in order to identify the fungi that were isolated. Six cultures of the two fungal species that were isolated consistently from the tissue were sent to CABI Bioservices, UK for confirmation of identification. These cultures included isolates from the stem and leaves and from both provinces of Burkina Faso that were surveyed. The isolates were identified using partial internal transcribed spacer ribosomal DNA sequencing analysis.

Koch's postulates. Koch's postulates were then undertaken, to establish the pathogenicity of the two species of Colletotrichum that were isolated consistently from branch chlorosis at all the sites where the disease was found. An isolate of each of these two species, the identity of which had been confirmed, from Mouna were selected for testing. They were grown separately on PCA, as described above. After 10 days, spores were dislodged from the surface of the agar using a curved glass rod and suspended in SDW containing Tween 80 (Polysorbate 80 ) at $0.01 \%$ (vol $/ \mathrm{vol}$ ) $(\mathrm{SDW}+\mathrm{T})$, at a concentration of $1 \times 10^{6}$ spores $\mathrm{ml}^{-1}$. Seedlings were grown from seed collected in Burkina Faso and potted-up in the following soil mixture: $5 \%$ vermiculite, $20 \%$ sand, $50 \%$ John Innes number 3 , and $25 \%$ multipurpose peat-based compost. Plants were maintained in an air-conditioned, quarantine greenhouse chamber set at $22 \pm 5^{\circ} \mathrm{C}$, with supplemented lighting set at a 12-h light-and-dark cycle (metal halide, full spectrum, light intensity of 8,000 to 13,000 Lux).

Twenty-one seedlings of $J$. curcas were selected and propagated in 15 -by-20-cm pots until approximately $30 \mathrm{~cm}$ tall, when each plant had at least three pairs of true leaves. The plants were randomly divided into three groups. One group was inoculated with Colletotrichum sp. 1, another with Colletotrichum sp. 2, and the third group was the control. The spore suspensions were brushed onto all aerial parts of the plants using a number 4 Humbrol Senator camel hair brush (approximately $2 \mathrm{ml}$ per plant); the control plants were brushed with the spore carrier only (SDW+T). Plants were placed in a dew chamber (Mercia Scientific) for $48 \mathrm{~h}$ following inoculation. Plants were then transferred to the quarantine greenhouse chamber and placed on the bench, their position being selected at random, and maintained as above. This experiment was repeated on a second set of plants, the only difference being that some of the leaves and stems were damaged by pricking with a hypodermic needle just prior to inoculation. Three leaves per plant (fully expanded, still expanding, and just unfurling) were pricked twice each, once on each side of the midrib (approximately half way between the midrib and the lamina edge); in addition, one prick on the petiole was also applied. The stems were pricked three times within a 1-by-2-cm area on three parts of the stem: just below the meristem, $4 \mathrm{~cm}$ above the soil level, and half way between these areas.
Because stem infections were rare with the aforementioned technique, a more severe method was used to induce stem cankers in a second inoculation experiment. Fifteen plants were produced as described above and randomly divided into three groups; a wound was made on each plant by cutting a 5-mm-diameter section of outer stem (approximately $2 \mathrm{~mm}$ thick), just below the growing point of the seedling. Five agar plugs $(5 \mathrm{~mm}$ in diameter) were taken from 10-day-old cultures of Colletotrichum sp. 1 and one plug was placed on the wound of each of five plants in one group. This was repeated for Colletotrichum sp. 2 and a second group of freshly wounded plants. Control plants had agar plugs only placed on the wounds. The plugs were kept in place using Parafilm for 3 days. Plants were maintained in the quarantine chamber within a plastic greenhouse to increase the relative humidity to approximately $80 \%$; the position of each plant was selected at random.

\section{Results}

Survey. Diseased jatropha plants were found to have areas of infection on the leaves, stems, and fruit (Fig. 1A), confirmed by laboratory isolation from the different infected plant parts. Leaf lesions started on the younger leaves as chlorotic spots over the lamina surface, the leading edge of which expanded more quickly along the veins, giving a characteristic dendritic appearance to the lesions (Fig. 1B). Necrosis was then observed to develop around the lesions, down the veins, and particularly down the midrib. The leaves then started to senesce; demonstrating typical "green islands" around the lesions, which subsequently coalesced as necrosis developed across the lamina (Fig. 1C). It was possible to use this characteristic infection pattern to find early-stage branch infection (chlorosis), because chlorosis, in most cases, was found on branches that had leaf infection. Infections on the branches appeared to start as chlorotic areas, followed by necrosis and canker formation. Branch death was observed in two forms: either the branch lodged once the canker had girdled it or, if the infection was close to the tip of the branch, the whole branch was observed to die back (Fig. 1A). Either way, no fruit yield was obtained from above the canker. Lesions were also observed on the pericarp of the fruit (Fig. 1A), which was likely to affect yield even if the branches were not infected below the fruit bunches.

In both Sissili and Comoé, the disease was widespread; however, in Comoé, no fields with high disease incidence were encountered (Table 1). In Sissili, early-season infection at three of the sites had resulted in almost no fruit yield. Regrowth was visible from below the branch cankers but new infections on these branches were also apparent (Fig. 2A). The disease was observed not to progress far within stem tissue that was lignifying and, hence, infection mainly spread up the young, fast-growing branches. At sites with low disease severity, infected plants were generally observed at the edge of the field, suggesting wind or insect dispersal between sites Mature trees of the commercially and culturally important shea tree (Vitellaria paradoxa) are commonly found within jatropha fields. Observations were made but not measured that disease incidence was higher on the jatropha under these trees, probably due to the increased humidity in the shaded conditions encouraging pathogen infection. Plants that received fertilizer also had a high disease incidence, as did plants grown with intercropping or as hedging plants. In these cases, plants were receiving fertilizer directly or indirectly for the crop being grown close by and, thus, had far more young, susceptible tissue available for infection. The plants

Table 1. Disease incidence on Jatropha curcas observed at the survey sites in Burkina Faso

\begin{tabular}{lccccc}
\hline & & \multicolumn{4}{c}{ Number of sites showing disease incidence rating $^{\mathbf{a}}$} \\
\cline { 3 - 6 } Province & Surveyed $^{\mathbf{b}}$ & High & Medium & Low & ND \\
\hline Sissili & 11 & 3 & 4 & 2 & 2 \\
Comoé & 7 & 0 & 1 & 4 & 2
\end{tabular}

${ }^{\mathrm{a}} \mathrm{High}=>80 \%$ of trees with at least one branch infected, Medium = symptoms visible on 80 to $20 \%$ of trees, Low $=$ symptoms visible on $<20 \%$ of trees, and $\mathrm{ND}=$ no disease observed.

${ }^{\mathrm{b}}$ Number of sites surveyed. 
in abandoned fields had very poor growth and low levels of disease incidence and were usually infested with the flea beetle, Aphthona whitfieldi (Chrysomelidae).

Field monitoring. Symptom development was recorded on all but one of the 30 replicate stems during the 7-week monitoring period. The results confirmed that stem chlorosis represents the early stage of disease development (Table 2). It was found that, over the monitoring period, the disease symptoms progressed from chlorosis through a necrotic phase and, in approximately $83 \%$ of replicates, stem cankers then developed. The position of the canker influenced the final stage of disease development: those cankers higher on the stems caused stem dieback; branches with lower infections tended to lodge (Fig. 1A). Infections that developed close to lignified tissue sometimes did not develop into cankers. Speed of disease progress varied between replicates. In 10 of the 29 infections monitored, branch death was recorded and another 13 stems were moribund. In only four stems (approximately 14\%), the disease appeared to be contained and, on those stems, some yield may have been harvested. In at least 12 of the 29 replicate infections (approximately 41\%), a clear puncture wound was visible at the center of the initial chlorosis (Fig. 2B).

Isolation and identification. Two Colletotrichum spp. were consistently isolated from the stem infection: one with straight cylindrical conidia, obtuse at the apex, and one with falcate co- nidia; both were produced in acervuli. Only the falcate spore type was isolated from the leaf lesions and the puncture wound. All six cultures that were sent for identification to CABI Bioservices were found to belong to two species of Colletotrichum. The results from a BLAST search against the GenBank sequence database showed a $100 \%$ similarity with two known species: the "anthracnose" causing pathogen Colletotrichum truncatum (Schwein.) Andrus \& W.D. Moore (=C. capsici) IMI 502236 and a member of the species complex C. gloeosporioides sensu lato IMI 502235 (10). There are currently 22 species recognized in this species complex and members can be pathogenic, saprophytic, and endophytic.

Koch's postulates. Young leaves, still within the meristematic area, of all seedlings inoculated with $C$. truncatum were necrotic, with some mycelial growth visible on the surface of the leaves $48 \mathrm{~h}$ after inoculation (i.e., upon removal from the dew chamber); this is indicative of the production of a toxin by the fungus. Chlorotic lesions appeared on the developing leaves of all seedlings inoculated with $C$. truncatum 7 days after inoculation; these developed into necrotic spots (Fig. 3A). The damaged leaves in the meristematic area shriveled and fell from the plant (Fig. 3B). No symptoms were observed on those plants inoculated with C. gloeosporioides or on the control plants. Stem lesions did not develop following pricking of the stem before inoculation for either fungus,
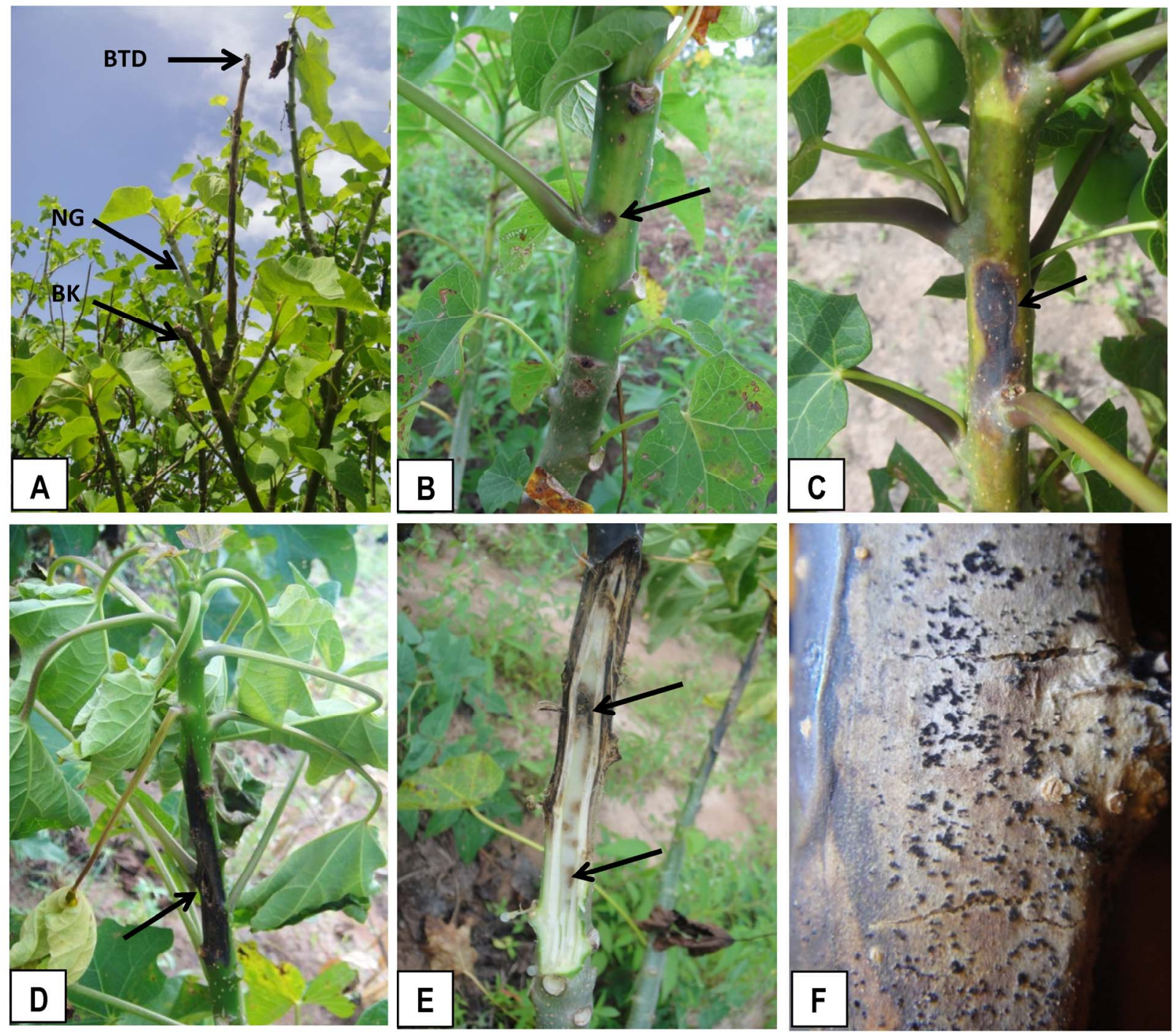

Fig. 2. Jatropha curcas branches infected with Colletotrichum truncatum showing symptom development in the field. A, Regrowth pattern following branch infection (BK = branch killed by early season infection, BTD = branch tip dieback from infection of regrowth below first attack, NG = new growth from below second attack); B, chlorosis, with wound visible at the center (arrow); C, actively developing necrosis (arrow); D, canker development (arrow); E, longitudinal section through leading edge of canker showing internal necrosis (arrows); F, C. truncatum sporulating on branch canker, acervulae with many setae visible as black masses. 
and there was no significant difference observed in leaf infection between pricking and not pricking for either fungus tested.

However, the wounding experiment was partially successful, although the severe symptoms observed in the field were not reproduced. After approximately 2 weeks postinoculation, necrosis had started to develop on four of the five wounded shoots that were inoculated with C. truncatum (Fig. 3C). Necrosis was not observed to develop on the control plants and only one of the plants inoculated with $C$. gloeosporioides started to develop lesions around the wound.

Sections of stem were cut from the lesions that had developed around the wounds inoculated with $C$. truncatum and the one $C$. gloeosporioides replicate. These were surface sterilized (as described in Material and Methods) and then placed on TWA + antibiotics. In all cases, $C$. truncatum was produced on the cut section (Fig. 3D), indicating that this pathogen was responsible for the symptoms. The control shoots, inoculated with agar plugs only, and four of those plants inoculated with $C$. gloeosporioidesinfected plugs developed callous tissue over the wound, and no lesions developed (Fig. 3C); the plants continued to grow normally. Because this latter fungus was isolated along with $C$. truncatum from almost every stem sample, it is posited that $C$. gloeosporioides is a benign or nonpathogenic, possibly endophytic, fungus within the plants.

\section{Discussion}

There is now increasing evidence that jatropha is highly susceptible to pests and diseases and that these may seriously affect plant growth and yield. Colletotrichum spp. have now been recorded to cause diseases of jatropha wherever it grows (5). The diseases are considered to be restricted mainly to the leaves and fruit, causing leaf anthracnose and fruit rot and mummification $(4,8)$. However, $C$. capsici (synonym C. truncatum) was reported to infect seedlings in Yucatan, Mexico, where the disease not only caused foliar necrosis and defoliation but also crown canker and apical death of the seedlings (9). From the present field observations in Burkina Faso and the glasshouse-based studies in the United Kingdom, a strain of C. truncatum is emerging in West Africa that is able to cause severe canker formation on the new stem growth of $J$. curcas. The jatropha plantings in West Africa have a restricted genetic diversity (3). Therefore, once a pathogen has adapted to a new host, it can be easily dispersed throughout an area, although long-distance dispersal tends to be human mediated. The Plantwise Diagnostic and Advisory service, based at CABI in the United Kingdom (http://www.plantwise.org/?page $=4347 \&$ site $=234$ ) also received samples of diseased jatropha from Ghana in June 2013. The symptoms were concurrent with those observed in Burkina Faso, and the same two fungi ( $C$. truncatum and $C$. gloeosporioides) were isolated from young diseased tissues. This provides evidence that this serious disease is now spreading in the region, and that phytosanitary procedures need to be implemented to help prevent further spread of the pathogen. An integrated pest management approach should be developed to mitigate the impact of this pathogen within jatropha cropping systems.

Thus far, the disease has only been found to cause leaf lesions and cankers on young stems. It was found not to progress within the lignified stem tissue; there was no evidence that the disease progressed down the stems but only upward into the younger tissue. Therefore, cultural control using carefully targeted pruning could successfully be employed to manage this disease. Although

Table 2. Symptom development on diseased stems of Jatropha curcas monitored in the field over a 7-week period (26 September to 14 November 2012 ), in Burkina Faso

\begin{tabular}{|c|c|c|c|c|c|c|c|c|c|}
\hline \multirow[b]{2}{*}{ Plot, stem } & \multicolumn{8}{|c|}{ Symptoms at days after branch tagging ${ }^{\mathrm{a}}$} & \multirow[b]{2}{*}{ Comments $^{b}$} \\
\hline & $\mathbf{0}$ & 7 & 14 & 21 & 28 & 35 & 42 & 49 & \\
\hline \multicolumn{10}{|l|}{1} \\
\hline $1-1$ & 2 & $\mathrm{n} / \mathrm{r}$ & 2 & 3 & 3 & 3 & 4 & 4 & Disease progress curtailed \\
\hline $1-2$ & 1 & $\mathrm{n} / \mathrm{r}$ & 3 & 6 & 6 & 6 & 6 & 6 & Close to lodging \\
\hline $1-3$ & 2 & $\mathrm{n} / \mathrm{r}$ & 2 & 2 & 2 & 3 & 3 & 5 & Disease progress curtailed \\
\hline $1-4$ & 1 & $\mathrm{n} / \mathrm{r}$ & 1 & 1 & 1 & 1 & 3 & 5 & Disease progress curtailed \\
\hline $1-5$ & 1 & $\mathrm{n} / \mathrm{r}$ & 3 & 5 & 5 & 5 & 5 & 5 & Disease progress curtailed \\
\hline $1-6$ & 1 & $\mathrm{n} / \mathrm{r}$ & 4 & 6 & 6 & 6 & 6 & 6 & Close to lodging \\
\hline \multicolumn{10}{|r|}{ 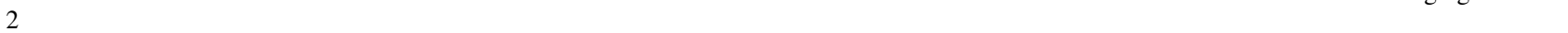 } \\
\hline $2-1$ & 1 & $\mathrm{n} / \mathrm{r}$ & 2 & 3 & 4 & 6 & 6 & 6 & Close to lodging \\
\hline $2-2$ & 2 & $\mathrm{n} / \mathrm{r}$ & 3 & 4 & 4 & 6 & 6 & 6 & Close to lodging (W) \\
\hline $2-4$ & 2 & $\mathrm{n} / \mathrm{r}$ & 3 & 3 & 4 & 6 & 6 & 6 & Close to lodging \\
\hline $2-5$ & 2 & $\mathrm{n} / \mathrm{r}$ & 4 & 6 & 7 & 7 & 7 & 7 & Dieback (W) \\
\hline $2-6$ & 2 & 3 & 4 & 6 & 6 & 6 & 6 & 6 & Close to lodging (W) \\
\hline \multicolumn{10}{|l|}{3} \\
\hline $3-1$ & 2 & 3 & 6 & 6 & 6 & 6 & 6 & 7 & Dieback (W) \\
\hline $3-2$ & 1 & 1 & 3 & 4 & 5 & 5 & 5 & 7 & Dieback \\
\hline $3-3$ & 2 & 3 & 3 & 4 & 4 & 6 & 6 & 7 & Dieback (W) \\
\hline $3-4$ & 1 & 1 & 3 & 3 & 4 & 6 & 6 & 7 & Dieback (W) \\
\hline $3-5$ & 2 & 3 & 3 & 4 & 4 & 6 & 6 & 7 & Dieback (W) \\
\hline $3-6$ & 2 & 3 & 4 & 6 & 6 & 6 & 6 & 6 & Close to full dieback (W) \\
\hline \multicolumn{10}{|r|}{ 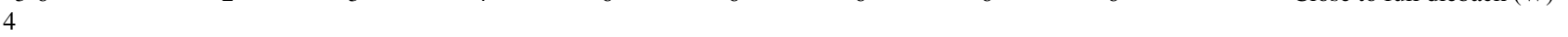 } \\
\hline 4-1 & 1 & 1 & 3 & 4 & 4 & 5 & 5 & 5 & $(\mathrm{~W})$ \\
\hline $4-2$ & 1 & 3 & 4 & 6 & 6 & 6 & 6 & 6 & Close to lodging \\
\hline $4-3$ & 1 & 3 & 4 & 6 & 6 & 6 & 6 & 6 & Close to lodging (W) \\
\hline $4-4$ & 1 & 1 & 4 & 6 & 6 & 6 & 6 & 6 & Close to lodging \\
\hline $4-5$ & 1 & 3 & 4 & 6 & 6 & 6 & 6 & 6 & Close to lodging (W) \\
\hline $4-6$ & 1 & 3 & 6 & 6 & 6 & 6 & 6 & 6 & Close to lodging (W) \\
\hline \multicolumn{10}{|r|}{ 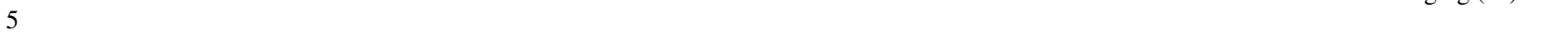 } \\
\hline $5-1$ & 1 & 2 & 2 & 4 & 4 & 6 & 6 & 7 & Dieback \\
\hline $5-2$ & 1 & 2 & 4 & 6 & 6 & 6 & 7 & 7 & Dieback \\
\hline $5-3$ & 1 & 3 & 4 & 6 & 6 & 6 & 7 & 7 & Dieback (W) \\
\hline $5-4$ & 1 & 2 & 4 & 6 & 6 & 6 & 6 & 6 & Close to lodging \\
\hline $5-5$ & 2 & 4 & 6 & 6 & 6 & 7 & 7 & 7 & Lodged $(\mathrm{W})$ \\
\hline $5-6$ & 2 & 3 & 4 & 4 & 6 & 6 & 6 & 6 & Close to lodging (W) \\
\hline
\end{tabular}

a Symptom key: $1=$ mild chlorosis; $2=$ severe chlorosis; $3=$ severe chlorosis and mild necrosis; $4=$ necrosis, actively developing; $5=$ necrosis, infection contained, stem survival likely; $6=$ canker development; 7 = branch lodging or dieback from tip of branch; and $\mathrm{n} / \mathrm{r}=$ no record.

$\mathrm{b}(\mathrm{W})=$ wound visible at center of infection. 
further research is urgently needed to develop best management practices for the disease, based on the current information, the following measures are recommended. Jatropha plants in fields that had the disease in the previous year should be pruned well below the stem cankers (no necrosis visible in the remaining part of the cut stem), and the cuttings should be burned. Pruners should be disinfected between each tree. This should be carried-out at the normal pruning time, in the dry season (December to January in Burkina Faso), when there is less likely to be inoculum available. Fields should be carefully monitored when the plants start to regrow and any disease stems pruned, as above. Effective management of this disease requires early detection. $C$. truncatum is recorded to attack a number of different crops in the bean family (Fabaceae) and those belonging to the family Solanaceae. This is a potentially significant issue when intercropping plant species from these families with jatropha, particularly bean cultivars which are commonly grown in West Africa. Intercropping with bean, chili, tomato, and aubergine should be avoided in fields where the disease occurred in the previous year, because a single strain of $C$. truncatum may be able to infect a number of different plant species.

The judicious use of protectant fungicides (e.g., Carbendazim, Mancozeb, or Chlorothalonil) has proved to be effective in preventing infection by Colletotrichum spp. on other crops (2). Fungicides registered for use on jatropha in affected countries could be applied to jatropha early in the growing season while the plant biomass is still low and the tissue likely to be most vulnerable to infection. However, the cost of fungicide use may be prohibitively expensive for small-holder farmers, particularly on a crop that is promoted as being relatively low input and with the current low prices commanded for the seed. Because it is the young tissue that is the most susceptible to the disease, it is also important that fertilizer should be applied in small amounts over the growing season, to prevent overstimulation of vegetative growth. However, this is more work for farmers. In the long term, it is important that tolerance or resistance to $C$. truncatum is included in plant breeding programs.

Field observations found that over $40 \%$ of stem infections are associated with a puncture wound and the causal agent of the disease was isolated from a wound. Although not conclusive, this suggests that the pathogen may be insect vectored; for example, passively on the mouth parts of true bugs feeding on the growing point of jatropha branches. The rainbow shield bug Calidea dregii (Scutelleridae) was commonly observed feeding on jatropha. Thus, it may also be important to minimize the impact that insects may have in vectoring this disease; for example, by the application of systemic pesticides at times when the bug is most prevalent.

Despite these recommendations, the major issue remains that, at present, jatropha is not sufficiently productive and profitable to
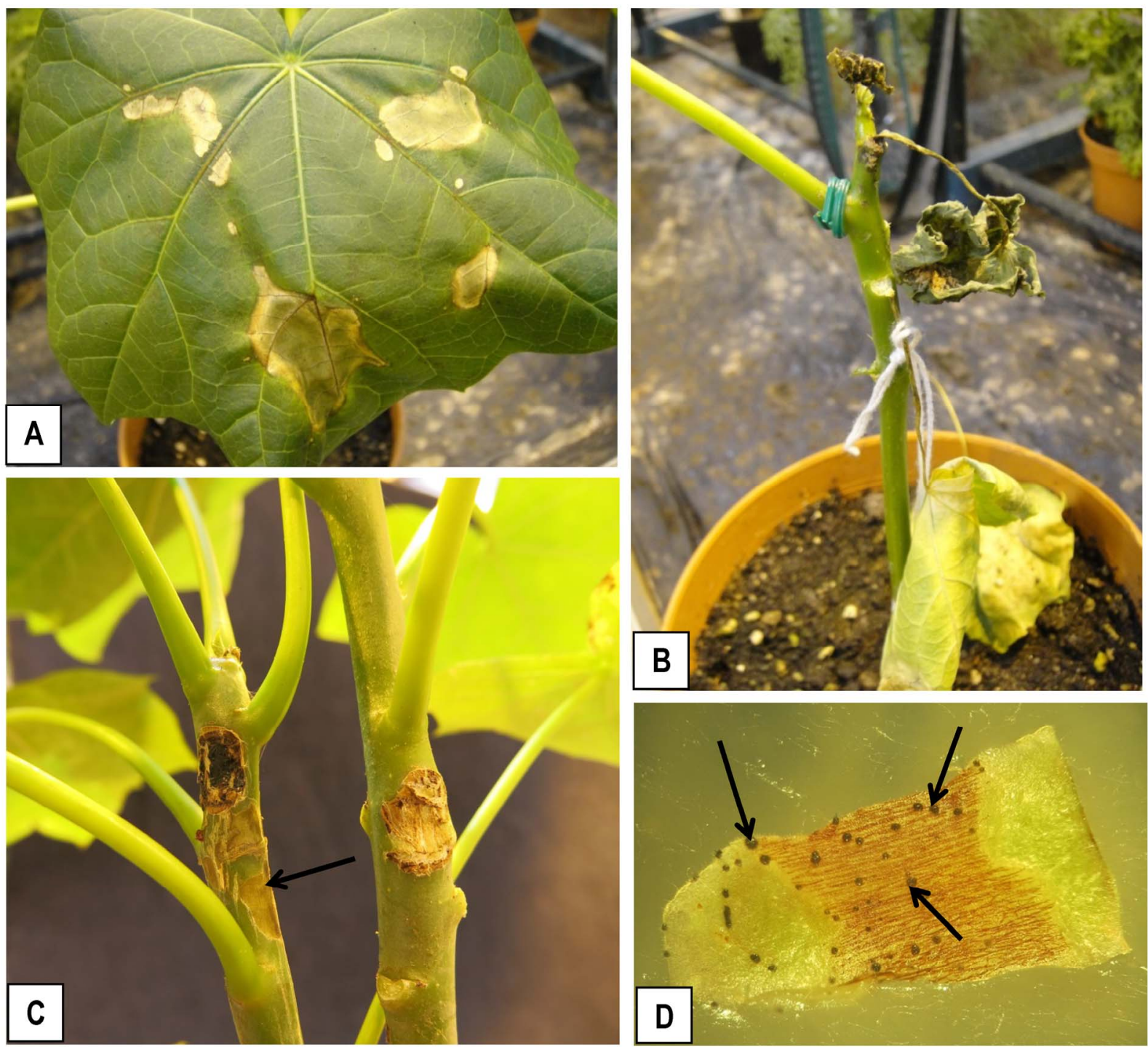

Fig. 3. Jatropha curcas seedlings inoculated with Colletotrichum truncatum. Spores brushed onto seedlings: A, leaf infection and B, death of inoculated leaves and tip necrosis. Agar plug inoculation of stems: C, plant on right is the control, plant on left inoculated with fungus (arrow shows necrotic development); D, section taken from necrotic area on stem showing development of $\mathcal{C}$. truncatum acervulae (arrows). 
encourage farmers to adequately care for the crop without subsidy. This situation may change as, for example, higher-yielding varieties are bred and become available to farmers or if the price for the seed rises sufficiently to warrant farmers investing in the care of the crop, which may happen if the price of crude oil increases. Unfortunately, in the short term, it is likely that farmers will continue to neglect jatropha fields in significant areas where it is being promoted in sub-Saharan Africa (6).

\section{Acknowledgments}

We thank M. Diakité, N. Tiguéwordé, and colleagues from APROJER for their help during the surveys in Comoé Province; K. Pollard, in the United Kingdom, for providing excellent technical assistance; and H. Evans and R. Reeder for reviewing the manuscript. This work was undertaken under the ERA-ARD Biofuels Project 'Jatrophability' and the pathogen was held in the United Kingdom under DEFRA license number PHSI 139/6910 (11/1012).

\section{Literature Cited}

1. Anitha, K., and Varaprasad, K. S. 2012. Jatropha pests and diseases, an overview. Pages 175-218 in: Jatropha, Challenges for a New Energy Crop. N. Carels, M. Sujatha, and B. Bahadur, eds. Springer, New York.

2. Jeffries, P., Dodd, J. C., Jeger, M. J., and Plumbley, R. A. 1990. The biology and control of Colletotrichum species on tropical fruit crops. Plant Pathol. 39:343-366. Online publication. doi:10.1111/j.1365-3059.1990.tb02512.x

3. Jongschaap, R. E. E., Kenis, M., Ellison, C., Rouamba, M., and Freyer, B. 2013. Jatropha growth and oilseed production in Africa. Jatropha Facts Ser. Issue 1, ERA-ARD.

4. Kwon, J.-H., Choi, O., Kim, J., and Kwak, Y.-S. 2012. First report of an- thracnose disease on Jatropha curcas caused by Colletotrichum gloeosporioides in Korea. J. Phytopathol. 160:255-257. Online publication. doi:10. 1111/j.1439-0434.2012.01890

5. Machado, A. R., and Pereira, O. L. 2012. Major Diseases of the Biofuel Plant, Physic Nut (Jatropha curcas), in: Biodiesel—Feedstocks, Production and Applications, Prof. Zhen Fang ed. InTech. Online publication. doi:10. 5772/52336

6. Muys, B., Norgrove, L., Alamirew, T., Birech, R., Chirinian, E., Delelegn, Y., Ehrensperger, A., Ellison, C. A., Feto, A., Freyer, B., Gevaert, J., Gmünder, S., Jongschaap, R. E. E., Kaufmann, M., Keane, J., Kenis, M., Kiteme, B., Langat, J., Lyimo, R., Moraa, V., Muchugu, J., Negussie, A., Ouko, C., Rouamba, M. W., Soto, I., Wörgetter, M., Zah, R., and Zetina, R. 2013. Integrating mitigation and adaptation into development: The case of Jatropha curcas in sub-Saharan Africa. GCB Bioenergy Editorial 1-3. Online publication. doi: $10.1111 / \mathrm{gcbb} .12070$

7. Ritchie, B. J. 2002. Mycological media and methods. Pages 410-431 in: Plant Pathologist's Pocketbook. J. M. Waller, J. M. Lenné, and S. J. Waller, eds. CABI Publishing, Wallingford, UK.

8. Rodrigues dos Santos, G., José Tozze, H., Jr., Alves Corrêa de Sá, D., Quintão Furtado, G., and Sidnei Massola, N., Jr. 2013. Etiology and pathogenicity of two different isolates of Colletotrichum spp. obtained from physic nut seeds. J. Seed Sci. 35:139-146. http://dx.doi.org/10.1590/S231715372013000200001

9. Torres-Calzada, C., Tapia-Tussell, R., Nexticapan-Garcez, A., Matin-Mex, R., Quijano-Ramayo, A., Cortés-Velázquez, A., Higuera-Ciapara, I., and Perez-Brito, D. 2011. First report of Colletotrichum capsici causing anthracnose in Jatropha curcas in Yucatan, Mexico. New Dis. Rep. 23:6. http://dx.doi.org/10.5197/j.2044-0588.2011.023.006

10. Weir, B. S., Johnston, P. R., and Damm, U. 2012. The Colletotrichum gloeosporioides species complex. Stud. Mycol. 73:115-180. 